\title{
Industry chews over FDA liposome regulations
}

Drugs packaged in the enclosed cavity of a lipid bilayer (a "liposome") display different bioavailability, altered organ specificity, and different rates of clearance from those of the parent drug alone. Recent approval of liposome formulations of drugs like daunorubicin (NeXstar Pharmaceuticals, Inc., in Boulder, Colorado) - and the anticipation of more new drug applications to come -

\section{There is a doctor in the House}

For organized medicine, last month's national elections in the United States proved a mixed blessing. Of the 21 physicians running for the US House of Representatives (the highest number this century), only 7 were elected. The single physician in the Senate, transplant surgeon Bill Frist (Republican, Tennessee) was not up for reelection this year.

Despite the number of losses, however, physicians did increase their clout in Congress. All four physician incumbents retained their seats (plastic surgeon Greg Ganske, Republican, Iowa; internist Dave Weldon, Republican, Florida; obstetrician Tom Coburn, Republican, Oklahoma; and psychiatrist Jim McDermott, Democrat, Washington). These four will be joined by three freshmen when Congress reconvenes in January: Vic Snyder, an Arkansas Democrat and family physician, Louisiana Republican John Cooksey, an ophthalmologist, and Ron Paul, a Texas Libertarian and obstetrician.

The new wave of political officeseeking among physicians has been fueled in large part by the American Medical Association (AMA) and its political action committee, AMPAC. For a fee, a potential physician-candidate can enroll in AMPAC's "candidate training school," which will provide them with nuts-and-bolts campaign information, as well as a preview of what to expect on the campaign trail.

Of the 21 House races involving physicians, perhaps the most interesting were Paul's, because of his controversial views, and the contest featuring Richard Klein, a New York internist and Democrat, which gave a glimpse into the internal political workings of organized medicine in Washington, DC. are forcing the US Food and Drug Administration (FDA) to issue regulatory guidelines for liposomal drug delivery systems.

In June 1994, FDA's division of Antiviral Drug Products produced a draft of proposed guidelines (Points to Consider in the Development of Liposomal Drugs Intended for the Treatment of HIV Infection and Disorders.) In late October, represen-

\section{IMAGE UNAVAILABLE FOR COPYRIGHT REASONS}

Richard Klein, an internist and unsuccessful US congressional candidate, campaigns for votes at a "Golden Age Picnic."

A Republican congressman from 1976 to 1977 , and again from 1979 to 1985 , Paul was the Libertarian candidate for US President in 1988. Known for his controversial stands (most notably the legalization of drugs and a return to the gold standard), Paul has criticized the Medicare program as unworkable. He won his election over Democratic lawyer Charles "Lefty" Morris.

Klein, however, was defeated by the incumbent, Sue Kelly (Republican, New York). His campaign started as a crusade against managed care, which he called "one of the most despicable things that has ever happened." Although he campaigned as a Democrat, Klein said he was running "not as a Republican or a Democrat, but as a physician interested in protecting the interests of patients."

Although Klein's anti-managed care, pro-patient message seems a natural fit with the AMA's own agenda, he failed to garner AMA support. Indeed, the AMA supported Kelly, Klein's opponent. Klein said he was rebuffed when he contacted the AMA for support: "They said I was in the wrong party," he said. An AMA spokesman would not comment on how the group selects candidates it supports.

ERIC WEISSENSTEIN Washington, $D C$ tatives of both FDA and industry gathered at an open session of the American Association of Pharmaceutical Scientists meeting in Seattle, Washington, to discuss FDA's plans for final liposome guidelines.

Industry representatives had some concerns. For example, the 1994 draft originally called for detailed information on liposome structure, including phase transitions (or the "melting point"), charge distribution, volume of entrapment, and the structure of the lipid-drug complex. But subsequent studies have provided a better understanding of the structure and phase-transition temperatures of liposomes, says Suggy Chrai of The Liposome Company, Inc. (Princeton, New Jersey), who also presented at the meeting. Chrai argues that new drug formulations should not merit special consideration simply because they are liposomes.

Another recommendation from the 1994 draft drew fire from several industry representatives at the meeting. FDA proposed requiring measurements of "lamellarity," which is a descriptor of the number of lipid/water "layers" that can be peeled away from the onionlike structure of liposomes. Norman Weiner, a pharmaceutical scientist at the University of Michigan, shares the concerns. "I don't think [anyone] understands how lamellarity affects drug delivery, but because we can do it, people are asked to put that in [the application]," says Weiner. Despite the uncertainties of the lipid-drug interactions, liposomes - developed originally as model membranes - are perhaps better understood than any other drug delivery vehicle. "We know more about liposomes than we do about other (delivery) systems," says Weiner, "so why go through so many different potential regulatory issues?"

The FDA will circulate a new draft of proposed guidelines to industry before finalizing it by the end of next year. Most came away from the meeting optimistic that the FDA is taking appropriate steps to refine the guidelines. According to Manfred Fleschar, director of product development at Access Pharmaceuticals, Inc. in Dallas, Texas: "I think they're moving in the right direction."

JAMES KLING Bellingham, Washington 